\title{
Secondary Education During Lockdown Situation Due to Covid-19 Pandemic in Bangladesh: Teachers' Response on Online Classes
}

\author{
Zeba Farhana $^{1 *} \quad$ Sanjida Akter Tanni $^{2} \quad$ Sariya Shabnam $^{3} \quad$ Sabbir Ahmed Chowdhury ${ }^{1}$ \\ 1.Assistant Professor, Institute of Education and Research, University of Dhaka, Dhaka - 1000, Bangladesh \\ 2.Lecturer, Green University of Bangladesh, Dhaka- 1207, Bangladesh \\ 3.Student, , Institute of Education and Research, University of Dhaka, Dhaka - 1000, Bangladesh
}

\begin{abstract}
Online classes started in many secondary schools one month after the compulsory closure of all education institutions in Bangladesh. This study explores the current scenario as well as challenges of adaptation of online classes in secondary education in terms of teachers' experience. The study followed sequential exploratory mixed-method approach. Five secondary teachers were interviewed and 54 secondary teachers from 17 districts in Bangladesh were surveyed over telephone, Google forms and by email. The quantitative data was analyzed with Microsoft Excel and the thematic analysis approach had been followed for the qualitative one. The findings revealed that a good number of teachers have started teaching online by using social media platforms despite of not having any training or experience. Very few respondent teachers were found to take online examination; instead they are trying to assess the students from the feedback of given home works and home assignments. Teachers are facing numerous challenges like deficit of digital equipment, lack of expertise, unfamiliarity with the LMS, proficiency in assessment technique etc. The paper concludes with few recommendations such as providing proper devices to the teachers and students to participate in online class; facilitate rigorous training to enhance technology-based skills and capacities of the teachers so as to get the expected outcome.
\end{abstract}

Keywords: Secondary education, Education in pandemic, Online class, Teachers' response.

DOI: $10.7176 / \mathrm{JEP} / 11-20-11$

Publication date:July $31^{\text {st }} 2020$

\section{Introduction}

Government of Bangladesh (GoB)'s lockdown restrictions have resulted in closing down of all schools and educational institutions in the country since 18 March 2020 (GoB, 2020). As a result, 42 million students are no longer able to attend school and might be prevented from doing so until September 2020 (Unicef, 2020). Shortly after schools were closed, GoB started broadcasting pre-recorded secondary level school lessons titled 'My School at My Home' in national television channel with the help of government agency 'Access to Information (a2i)' to assist the school children continue their learning during the pandemic. Besides, GoB also encouraged and instructed the schools and colleges to initiate online classes for their students (GoB, Directorate of Secondary and Higher Education, 2020). In response, many secondary schools have started taking online classes by using available means.

GoB has already established 24,816 multimedia classrooms, provided internet connection to almost $90 \%$ schools and set up multimedia classroom monitoring system (a2i Programme GoB, 2018), but these infrastructures could not be utilized to take online classes as the schools are closed during lockdown period. Taking online classes for secondary education are not that easy in a developing country like Bangladesh, because the technology and equipment required to participate in an online class are not cheap. It requires availability of technological infrastructures like internet connection, computer with camera and microphone or a smart phone both for the teachers and students (Habib et al., 2020). 60\% people of Bangladesh have access to internet and $92 \%$ of them use mobile network for using internet (BTRC, 2020). But speed of internet varies widely in urban to rural area (Sohail, 2020). Price of internet and minimum required gadgets for participating in online classes is also beyond the reach of most of the students in Bangladesh (Azad, 2016).

Online learning is also influenced by computer knowledge of teachers and students, instructional methods of teachers, administration's mindset, policy frameworks, and technical assistance (Srichanyachon, 2014). The quality of teachers and their continuing professional education and training remain central to the achievement of quality education (Ministry of Education GoB, 2013). Understanding this fact, GoB regularly arranges teachers' training on ICT (Mamataz, 2017; PMID, 2013). Moreover, Digital Content development has also been undertaken so that all teachers can collect subject based contents from a single source, for which an official web portal titled Shikkhok Batayon has been opened (Mamataz, 2017; Ministry of Education GoB, 2013; PMID, 2013; Shikkhok Batayon, 2018). However, taking online class is totally new to most of the secondary teachers in Bangladesh, because it is absolutely unprecedented. Starting online classes without preparation and proper pedagogy, it would be less interactive and ineffective. The teachers need to be skilled at ICT in both the 
multimedia classes and the online classes. The user of multimedia needs knowledge and experience about it as well as one or two multimedia software. But in the online class, one needs to know where and how to find materials, how and when to use it for teaching-learning purposes, how to present educational content in the online platform, how to use multimedia products and online services in education (Andre \& Brink, 2013). Most of Bangladeshi secondary teachers have never been trained on these issues. With this backdrop, the aim of this study is to evaluate the responses of the secondary school teachers on taking online classes during lockdown Situation due to Covid-19 Pandemic in Bangladesh.

\section{Purpose and Research Questions of study}

The Purpose of the study is to evaluate the response of secondary school teachers in adaptation of online classes during the lockdown period due to COVID-19 pandemic in Bangladesh. The study evolves in answering the following research questions:

1. What is the situation of teaching learning activities during COVID-19 emergency?

2. How are secondary school teachers adapting in taking online classes?

3. What are the challenges teachers facing while taking online classes?

\section{Methodology}

The research framework led us methodologically to design a sequential exploratory mixed method according to research objectives to explore the phenomena. A survey questionnaire was used to collect quantitative data from 54 teachers of 54 different secondary schools selected randomly from 17 different districts in Bangladesh via Google forms, emails and mobile phones. The survey questionnaire was divided mainly into two parts, where the first part dealt with the demographic information of the teachers. The second part was designed to gather information about their knowledge on ICT, pedagogical application in conducting online class, online assessment method, their experience and challenges. Qualitative data were collected by in-depth interview over mobile phone from 05 teachers purposively selected from the above group. Quantitative data was analyzed using Microsoft Office Excel and thematic analysis was carried out for analyzing qualitative data.

\section{Findings}

In this following section the findings from the teachers' survey and interviews had been showed.

\subsection{Demographic Data}

Table 1. Profile of Surveyed Teachers $(\mathrm{N}=54)$

\begin{tabular}{|l|c|c|}
\hline Variables & & Percentage \\
\hline \multirow{3}{*}{ Gender } & Male & $52 \%$ \\
\cline { 2 - 3 } & Female & $48 \%$ \\
\hline \multirow{4}{*}{ Teaching Experience (years) } & $<=5$ & $24 \%$ \\
\cline { 2 - 3 } & $6-10$ & $24 \%$ \\
\cline { 2 - 3 } & $11-15$ & $20 \%$ \\
\cline { 2 - 3 } & $16-20$ & $24 \%$ \\
\cline { 2 - 3 } & $20>$ & $8 \%$ \\
\hline \multirow{2}{*}{ Trained on ICT } & Yes & $76 \%$ \\
\hline \multirow{2}{*}{ Experience of Taking Multimedia Class } & No & $24 \%$ \\
\cline { 2 - 3 } & Yes & $48 \%$ \\
\hline \multirow{2}{*}{ Type of Secondary School } & No & $52 \%$ \\
\cline { 2 - 3 } & Government & $46 \%$ \\
\cline { 2 - 3 } & Private & $54 \%$ \\
\hline
\end{tabular}

\subsection{Secondary Teachers' Adaptation of Online Classes}

Most of the teacher's attitudes are positive towards taking online classes. Eight seven percent teachers opined that online classes are necessary during pandemic. In this way, they are getting the opportunity to be engaged to their studies which will minimize the loss due to closure of schools for such a long period. It is revealed from the interview that the schools started taking online classes as early as from the 3rd week of April, one month after the closure of nationwide secondary schools on 18 March 2020. Almost 81\% respondent teachers were taking online classes regularly. Two-thirds of the teachers mentioned that more than $60 \%$ students were attending the online class and that is less than that of the regular class. 59\% teachers are using broadband connection and the rests are relying on cellular data for taking online classes. They are using different electronic gadgets like computers, laptops, smart phones, speakers, microphones to conduct the online classes. Smart phone is the most preferred gadgets among the teachers (49\%) for taking online class and $37 \%$ teachers are using 
computers/laptops. $14 \%$ teachers are using microphones/speakers/headphones in the online class.

None of the teachers have any previous experience of taking online classes. However, 76\% respondent teachers had training on ICT arranged either by GoB or their schools or on personal interest. Besides, $48 \%$ teachers had experience of taking multimedia class in their school. Most of the teachers got one or two week preparatory time for starting online class preparation. They utilized their previous knowledge of ICT and acquired further essential knowledge and skill of taking online class from their colleagues, friends, family members, and personal initiatives by surfing different web platforms like Youtube, Facebook etc. Teacher-1 mentioned, "I have learnt about online class from my children and mostly by taking self-initiative, but Govt and institutional training can be really effective for us." Teachers took initiatives to overcome these limitations and started taking online classes from 3rd week of April 2020. With the passage of time, they kept on improving their skills on taking online classes. The study found that respondent teachers are using several digital communicative platforms like Facebook Live, Whatsapp, Zoom and Viber as their instructional media for online class; details are shown in figure-1.

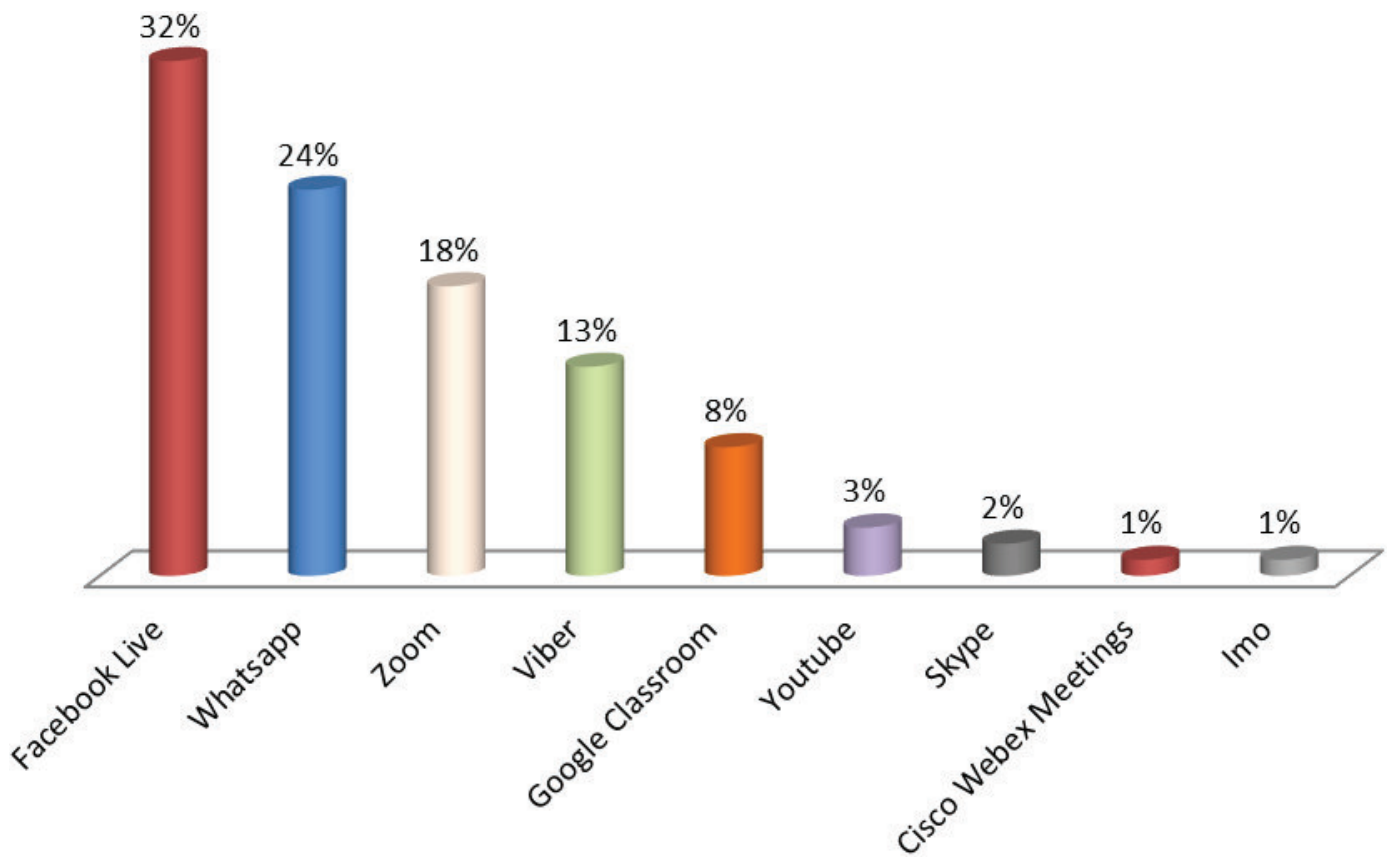

Figure 1. Usage of digital platforms for online class

\subsection{Teaching Methods, Materials and Pedagogy}

Teachers are using combinations of different teaching methods such as lecture, discussion, demonstration and group work to conduct online classes. Among these methods, lecture method is the most popular (65\%) as derived from the responses of teachers. Besides, $48 \%$ teachers mentioned that they used demonstration method and $33 \%$ teachers claimed to use discussion method to elaborate their topics. Teachers think discussion is the most effective teaching methods for secondary students rather than simple lecture. They also seldom used several teaching aids like images (26\%), videos (24\%) etc in online class to draw attention of the students. Most of the teachers mentioned that controlling online class is a bit difficult than controlling traditional classroom as they cannot talk to the students directly. So, they need to change teaching strategy frequently to make the class interactive. Some teachers are uploading PowerPoint slides, images, and different web links to their social media groups beforehand so that the students can acquire prior knowledge on the subject. Teachers opined that such uploads also help the students, who missed the class. A few teachers $(8 \%)$ tried to engage the students in various group works by using online platforms to enhance creative learning. Teacher-3 said, "Sometime I divide my students in few groups and give them small task to complete group wise. I found my students enjoy the group works". 


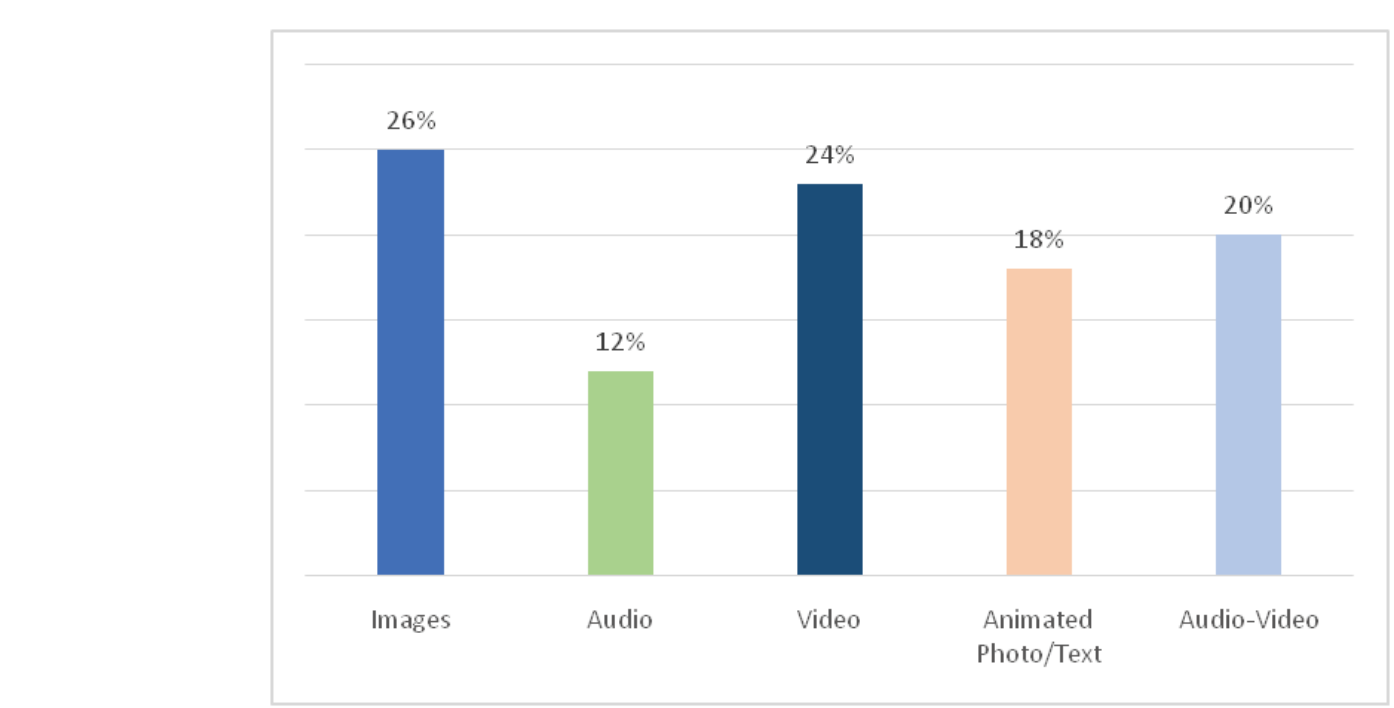

Figure 2. Teaching aids of online classes

\subsection{Assessment Methods}

During closure of school, scheduled class test and half early exam could not be arranged due to pandemic. Only $10 \%$ respondent teachers are taking online examinations of their students. $46 \%$ teachers are trying to assess the students from the feedback of given home works and home assignments to check student's improvement. Teacher-3 explained "Taking online exam is quite difficult as it's hard to get all the students at the same time to sit for the examination and it is cumbersome to keep track of the students during the examination". Teachers think that regular assessment is important to check students' progress as well as to keep them involved with the schooling process.Teacher-5 mentioned, "We encourage our students to submit their homework and assignment in time so as to keep them involved with the school".

\subsection{Challenges of Online Classes}

Teachers are facing numerous challenges while taking online classes. These challenges can be divided in to following groups:

4.5.1 Internet and Electricity

Slow internet speed (26\%), high cost of internet $(21 \%)$ and frequent power failures $(7 \%)$ are pointed out as the challenges of online class. Due to slow internet speed class progression is often slowed down. Teacher-3 mentioned, "Most of the time our classes are interrupted for poor network speed, it is so tiring and depressing to repeat same content". Beside, many teachers and students cannot afford to buy internet for schooling purpose due to their socioeconomic condition. Here, teacher-4 said, "For rural people, internet cost is costlier as the broadband connection is not available and many families cannot afford it. More so, they don't have necessary gadgets and their children are unable to join online class. To include these students, we prefer recording classes and broadcast them through cable television." This limited internet access in remote areas is widening the digital divide among the urban and rural populace.

4.5.2 Non-availability of Required Gadgets

$13 \%$ of the respondent teachers did not possess any gadget for conducting online class; as such they are unable to take online class.Teacher-5 mentioned, "I do not have any computer or smart phone to conduct online class, thus I go to my school and use school computer and internet to conduct online classes". Teacher-2 expressed, "Generally most of the families do not possess electronic gadgets like computer, laptop and smart phone as these devices are expensive and beyond their reach. The families who have a computer/laptop or a smart phone, they have more number of users than the gadgets. As such, when one student is attending online class, his siblings of other grades are unable to attend their online classes for not having their own gadgets. In many houses, a single gadget is shared by many family members for different purposes like work from home, taking online classes as teacher, attending online classes as student, playing games etc." So gadget scarcity is a great challenge for arranging education through online means during emergency due to pandemic in Bangladesh.

4.5.3 Technological Conversancy

Learning management systems (LMS) such as Google classroom, Piazza, aTutor, OLAT are very new technology for the secondary teachers of Bangladesh. Instead, teachers are using social media platforms Facebook live, WhatsApp, Viber etc, which have many shortcomings as compared to other online teaching software systems. Moreover, all the participants of an online class are not properly conversant with the technology. Class is often hampered by erratic operation of gadgets by the teachers and students. 


\subsubsection{Class Management}

Most of the teachers mentioned that numbers of students seems more than that of the regular class due to appearance of so many windows in a single screen. Time management is also a major concern for teachers. Delivering or demonstrating a topic and at the same time monitoring the students' participations is quite challenging. Teachers are also concerned about students' short-attention span in the class. One teacher mentioned "Students often tend to talk with their friends in video calls and create a disturbance in the class". 4.5.6 Home Environment

Environment of home of some teachers and students is not friendly for online class. Some of them do not have a suitable space at home for online class and some home environments are chaotic due to presence of many people around. Absence of suitable home environment is perceived as a challenge of online teaching-learning by $20 \%$ respondent teachers.

\section{Discussion}

The vary purpose of the study was to find out the current situation of secondary education during the closure of regular schooling due to COVID-19 pandemic in Bangladesh and to explore the responses of the secondary teachers for conducting online classes in this unprecedented situation. Despite of not having any experience, teachers responded quickly with positive attitude to GoB's initiatives in starting online classes for their school students with whatsoever gadgets they have with them. Around $81 \%$ respondent teachers are taking online classes with the help of smart phones (49\%) and computers/laptops (37\%). A total 13\% teachers are unable to take online classes as they do not possess required gadgets, which is better than the fact that $15 \%-19 \%$ secondary school teachers in Bangladesh did not have access to computer or internet at school or at home (Farhana \& Chowdhury, 2019).

$76 \%$ teachers were trained on use of ICT in education and 48\% teachers had experience of taking multimedia class. It is evident from this findings that ICT training and experience of multimedia class acted as a strength of the teachers to take online classes without any formal training or guideline. Respondent teachers are using Facebook Live, Whatsapp, Zoom, Google classroom and Viber as instructional media. Although, a good number of LMS are available online for free, which can be utilized to create and administer online courses, host a virtual classroom, assign homework, and to monitor student progress (Westfall, 2020), the most of the secondary teachers in Bangladesh are unaware of these LMS. GoB may take initiative to introduce a convenient LMS for conducting online class.

Teachers are using combination of different teaching methods such as lecture, demonstration, discussion and group work to conduct online classes. They think that discussion is most effective for secondary students rather than simple lecture. Besides, use of digital contents like videos and images help online teaching learning. Teachers are also uploading PowerPoint slides, images, different web links to their class's social media groups so that the students can acquire prior knowledge on the subject before attending the class and also to help the absent students. The study finds that the teachers are unfamiliar about online assessment method. Only $10 \%$ teachers were found to take online examinations. $41 \%$ teachers are trying to assess the students from the feedback of given home works and home assignments to assess the students.

Teachers are facing challenges of slow internet speed and high price of internet data package which they can barely afford for taking online classes. Internet speed in Bangladesh is almost 40\% slower than average internet speed in the world (Molla \& Islam, 2019). This speed further slowed down as the consumption of internet has been increased by $25-30 \%$ compared with that of the normal times due to the pandemic (Islam, 2020). As such, online classes are suffering from slower internet. Irregular power failures often hinder online classes too. Many teachers complained that controlling online class is a bit difficult than real classroom as they cannot talk to the students directly. As such, teachers are trying several strategies to make the class interactive.

\section{Conclusion and Recommendations}

Overall, the study analyzed the current situation of online education on the secondary level during COVID-19 pandemic. The scenario viewed from the study that, it is difficult to conceive a vigorous pedagogy without any preparatory activities. Limitations and challenges encountered by the teachers in taking online class can be mitigated by institutional and governmental support. These supports are also needed to minimize imbalance of quality of online education versus traditional face-to-face secondary level education as well as to help both the teachers and students to cope with the inconvenience of sudden transition of the teaching-learning platform. To sum up, the current situation of online education on the secondary level is yet to get up to the mark since the preparatory gap is observable from the resulting facts and both teachers and students' are challenging by different hindrances. Finally it could be forecasted from the study that, online classes started due to COVID-19 pandemic might not be a transitional phase only, rather it might emerge as a new normal platform of education at the secondary level for preparing the students of the 21 st century.

To ease up the present difficulties, GoB may take initiatives in increasing the speed of internet for education 
purpose within affordable reach of teachers and students. A good numbers of teachers do not possess necessary gadgets like computer, laptop, smart phone etc. Government subsidy on electronic gadgets like computer/smart phones for educational use may reduce the economic burden of teachers and student, thus enhance teaching learning activities. Arranging rigorous training and formulating policy guidelines on online class may mitigate challenges faced by the teachers in terms of technological conversancy, online class management and unfavorable home environment.

\section{References}

a2i Programme GoB. (2018, April 08). Home. Retrieved June 20, 2020, from Multimedia Classroom Monitoring System: http://mmcm.gov.bd/

Andre, B. B., \& Brink, K. v. (2013). Multimedia in Education. Moscow: UNESCO Institute for Information Technologies in Education.

Azad, A. K. (2016, January 06). Overview of Internet Access in Bangladesh: Impact, Barriers, and Solutions. Retrieved June 27, 2020, from www.isoc.org: https://web.archive.org/web/20160103124803 /https://www.isoc.org/inet97/proceedings/E3/E3_1.HTM

Babu, R., \& Nath, S. R. (2017, June 30). Use of ICT in Secondary Education in Bangladesh: Policies and Practices. Newsletter ANTRIEP, p. 6.

BTRC. (2020, April 20). internet-subscribers-bangladesh-march-2020. Retrieved June 19, 2020, from Bangladesh Telecommunication Regulatory Commission: http://www.btrc.gov.bd/content/internetsubscribers-bangladesh-march-2020

Farhana, Z., \& Chowdhury, S. A. (2019). Use of ICT by Biology Teachers in the Secondary Schools: Bangladesh Perspective. Journal of Culture, Society and Development, 26-27.

GoB. (2020, March 16). Executive Order for Closure of Education Institute. Dhaka, Bangladesh: Ministry of Education, Government of Bangladesh.

GoB, Directorate of Secondary and Higher Education. (2020, April 01). Notices. Retrieved June 18, 2020, from DSHE: http://www.dshe.gov.bd/site/view/notices

Habib, M. A., Rashid, M. M., \& Malak, S. (2020, June 02). Online Education and Students of Public University. The Samakal.

Islam, M. Z. (2020, April 14). Mobile internet slowest in Bangladesh among 42 countries. The Daily Star.

Mamataz, I. A. (2017, March 05). Use of multimedia in classroom: Successes and challenges. Retrieved June 20, 2020, from The Daily Sun: http://www.daily-sun.com/printversion/details/209947/2017/03/05/Use-ofmultimedia-in-classroom:-Successes-and-chal

Molla, M. A., \& Islam, M. Z. (2019, February 06). Slow Internet Speed: Blame game is all they can offer. The Daily Star.

Sohail, E. (2020, April 10). Remote learning in the time of Covid-19 and beyond. Dhaka Tribune.

Srichanyachon, N. (2014). The Barriers And Needs Of Online Learners. Turkish Online Journal of Distance Education 15(3), 50-59.

Unicef. (2020, May 06). Students in Bangladesh adjust to remote learning via national TV during COVID-19 lockdown. Retrieved June 18, 2020, from Unicef: https://www.unicef.org/bangladesh/en/stories/studentsbangladesh-adjust-remote-learning-national-tv-during-covid-19-lockdown

Westfall, B. (2020, March 26). 5 Best Free LMS Software Systems for Online Teaching. Retrieved June 26, 2020, from Capterra: https://blog.capterra.com/free-lms-software-online-teaching/\#Methodology 